\title{
On the Role of Government in Integrated Disaster Risk Governance-Based on Practices in China
}

\author{
Peijun Shi* \\ State Key Laboratory of Earth Surface Processes and Resource Ecology, Beijing Normal University, Beijing 100875, China \\ Key Laboratory of Environmental Change and Natural Disasters, Ministry of Education, Beijing Normal University, Beijing 100875, China \\ Academy of Disaster Reduction and Emergency Management, Ministry of Civil Affairs and Ministry of Education, Beijing Normal University, \\ Beijing 100875, China
}

\begin{abstract}
This article outlines the roles of government in ensuring integrated disaster risk governance in China. In general, government plays important political, economic, cultural, and social roles in risk governance systems that include resource assurance, technical support, and disaster risk management. Three key aspects of governance relate to those roles: (1) Overall leadership. Politically, the government has a leading role for the overall rule and system design, including legislation, decision-making processes, and policy implementation mechanisms. Economically, the government's primary responsibility is to strengthen resource assurance, including coordinating development and disaster reduction, and providing support for disaster reduction activities. Culturally, the government must increase risk awareness through disaster reduction education, training, and practice of emergency response skills, disaster risk research, and technical development. Socially, the government is vital to the improvement of integrated management, including disaster, risk, and emergency management systems. (2) Engaging civil society. Politically, the government is charged with the responsibility to engage and collaborate with civil society, such as NGOs. Economically, it is the role of the government to consolidate governmental and community resources. Culturally, the government needs to give the same importance to the functions of majority and minority cultures alike. Socially, it is the duty of the government to coordinate advantaged and disadvantaged social groups. (3) International cooperation. The government has an international humanitarian role politically to carry out disaster reduction diplomacy; economically to strengthen the catastrophe financial assurance system; culturally to improve the world safety culture, disaster reduction education, and technology assurance systems; and socially to increase the capacity for international disaster relief and assistance and volunteer services.
\end{abstract}

Keywords China, disaster reduction, humanitarian aid, integrated disaster risk governance

\section{Introduction}

In recent decades, the issues of and research on governance in general and risk governance specifically have drawn

\footnotetext{
*E-mail: spj@bnu.edu.cn
}

considerable attention in responding to the global environmental and societal changes as well as their implications and impacts on how society copes with and manages emerging risks (Beck 1992, 2006; Biermann et al. 2012; IRGC 2005, 2008, 2009; Renn 2008; Renn, Klinke, and van Asselt 2011). Not surprisingly, for a complex concept like governance there are many definitions and perspectives. Broadly, the term refers to the overall architecture for the multitude of actors and processes that lead to collectively binding decisions (Renn, Klinke, and van Asselt 2011). Governance involves the rules and roles (or power relations) for the actors in the processes of both making decisions as well as implementing them. Those rules and roles can be both formal and informal. Central features or core principles of the governance concept, when targeting specific domains of issues to be governed, evolved into a multitude of more specific governance definitions. For instance, from an earth systems perspective, Biermann, Siebenhüner, and Schreyögg $(2009,3)$ define global environmental governance as "the interrelated and increasingly integrated system of formal and informal rules, rule-making systems, and actor-networks at all levels of human society (from local to global) that are set up to steer societies towards preventing, mitigating, and adapting to global and local environmental change."

Renn, Klinke, and van Asselt $(2011,231)$ define risk governance as "both the institutional structure and the policy process that guide and restrain collective activities of a group, society or international community to regulate, reduce or control risk problems." According to the risk governance framework developed by the International Risk Governance Council (IRGC 2005, 2008), the risk governance process operates within and across broadly two spheres-the management sphere that contains decisions on and implementation of actions and the assessment sphere that focuses on the generation of knowledge concerning a range of risks, from hazards and vulnerability to socioeconomic impacts. It consists of five main stages of activities: pre-assessment (or framing), interdisciplinary risk estimation, risk characterization and evaluation, risk management, and communication/ participation (Renn, Klinke, and van Asselt 2011). Understanding the roles of the various actors involved in those 
processes and activities is an essential aspect of understanding risk governance. The range of actors and the design of the processes vary a great deal depending on the specifics of the political systems as well as the socioeconomic and cultural contexts. The dynamics, structures, and functionality of risk governance processes vary among countries. The roles of any actor in risk governance are defined and regulated by the particular procedural mechanisms and structural configurations that are determined by the particular political, socioeconomic, and cultural conditions under which risk governance takes place.

Most of the risk governance literature to date is dominated by studies discussing technological hazards and new kinds of risks, whereas more traditional natural hazards and disasters are poorly covered (Walker et al. 2010). To contribute to the empirical cases on understanding the changing roles of government in risk governance under varying political and socioeconomic systems, based on recent practices in China in responding to the Wenchuan Earthquake and the Southern China Freezing Rain disasters in 2008 and the Yushu Earthquake and Zhouqu Landslide disasters in 2010, this article outlines the roles that the Chinese government plays in integrated disaster risk governance (IDRG) and discusses the differences, where possible, in comparison with other political and economic systems (Zheng 2009).

In China, IDRG is not only seen as an important tool in social management, but also a basic feature of sustainable development. In recent years, China has witnessed several large-scale disasters, presenting tremendous risks to lives and greatly affecting sustainable social and economic development. It is an important and urgent task for academics, as well as industrial, economic, and political circles, and society as a whole to find effective approaches to disaster risk governance, to increase the utilization efficiency of resources for disaster prevention and reduction, and to achieve peoplecentered, scientific, development (Shi et al. 2010).

Disaster risk governance involves all stages of disaster risk management (pre-, during, and post-disaster), appropriate resources (financial and technical resource assurance, institutional capacity, human resources, and social capital), and multiple actors (Shi et al. 2007) of which government, affected communities, the private sector, and the public (or civil society) are the most important ones. As the stakeholders of disaster prevention and reduction, the different actor groups have different roles even as they share common targets and missions in all segments of disaster risk governance (Shi 2009). As the legal representative of a country or region and the leader and manager of the operation of public utilities, the government plays important roles in complicated public management systems. Three key aspects of the Chinese government's role in integrated disaster risk management are highlighted and described - overall leadership, engaging civil society, and international cooperation. We also focus on the overall leadership role politically, economically, culturally, and socially that the government plays as leader, planner, promoter, and organizer of IDRG. The coordinating role of the government internally on the state-society interface received attention in terms of collaboration with nongovernmental organizations (NGOs) and consolidation of resources. The coordinating role of the government is further discussed externally with international humanitarian responsibility and cooperation with international organizations.

\section{The Leading Role of the Government in IDRG}

Under different political and economic systems, the government plays different roles in managing public affairs. But in terms of such public affairs as disaster risk governance, the government plays an important role in both countries with a capitalist market economy and a federal system such as the United States of America and countries with a socialist market economy and central power such as China, although the government does not play an equal role in IDRG during different stages of disaster management. In the same way that everyone is equal in the eyes of the law, a government must take responsibility for the well-being of all people in its disaster risk management. In an age of scientific development, the government must play a leading role in IDRG; this responsibility is part of the power granted to the government by the public.

\subsection{Leader of IDRG}

Politically, the government must take the lead in formulating the overall system, the policy making and implementation mechanisms, and legislation covering integrated disaster risk management. As a country with various natural disasters and serious disaster situations, China has paid attention to its legislation relating to the management of different natural disasters. Under the organization of the Legislative Affairs Office of the State Council, the Standing Committee of the National People's Congress has adopted several regulations regarding integrated disaster risk management. Especially in terms of disaster relief and emergency management, a complete set of laws and regulations have been established, representing the leading role played by governments at different levels. In view of the system design for emergency management, the Emergency Response Law of the People's Republic of China stipulates that the state establishes a system for the administration of emergency response, which is characterized mainly by unified leadership, all-round coordination, categorized control, allocating responsibility at different levels, and territorial jurisdiction. The State establishes an effective social mobilization mechanism, enhances all citizens' awareness of the importance of public security and risk prevention, and helps increase the ability of the entire society to avoid risks and provide assistance. The people's governments at the county level shall be responsible for responding to emergencies that occur within their own administrative areas; the people's government at the next higher level, which the 
people's governments of the said administrative areas are subordinate to, shall assume responsibility, or the people's governments at the next higher level of the respective people's governments of the said administrative areas shall jointly assume responsibility. The State Council shall, under the leadership of the Premier, study, decide on, and make deployment for, response to especially serious emergencies; it shall, in light of actual need, establish a national command for emergency response, which shall be responsible for work in this respect; and when necessary, it may send a work team to guide the relevant work. The State Council and the local people's governments at or above the county level shall be the leading administrative organs for response to emergencies, and their working bodies and specific duties of such bodies shall be defined by the State Council (Li 2007). From the above, it may be observed that the government takes full responsibility in integrated disaster risk management, being the responsible body and the organizational leader.

\subsection{Planner of IDRG}

Another important task of the government is to formulate different programs of integrated disaster risk management for various administrative areas. During the transition from a socialist planned economy to a socialist market economy, the Chinese government focused attention on its general planning, which involved public affairs and the improvement of the mode of scientific development from a people-center perspective. From the beginning of the twenty-first century, the central government has explicitly included disaster prevention and reduction planning in its general planning of national economic and social development and gradually increased government input into disaster prevention and control. Local governments at different levels have also gradually increased their disaster prevention and reduction input to improve the protection and adaptation capacity of the social and economic system to different disasters. After the outbreak of the severe acute respiratory syndrome in 2003, governments at all levels in China strengthened their emergency management. Not only has the Standing Committee of the National People's Congress formulated the Emergency Response Law of the People's Republic of China (P.R.C. Standing Committee of the National People's Congress 2007) but also the State Council has formulated the General Emergency Response Program for State Accidental Public Events (P.R.C. State Council 2006). Earlier, the China National Committee for the International Decade for Natural Disaster Reduction (IDNDR) formulated the Disaster Reduction Planning of the People's Republic of China (1998-2010) (P.R.C. IDNDR 1998), and the National Development and Reform Commission and National Disaster Reduction Committee formulated the National 12th Five-Year Integrated Disaster Reduction Plan (2011-2015) (P.R.C. National Development and Reform Commission and National Disaster Reduction Committee 2011). Upon the occurrence of serious and major natural disasters, the State Council formulated Guidelines for Planning of Recovery and Reconstruction after Freezing Rain Disaster (25 February 2008) (P.R.C. State Council 2008), Planning for Post-Disaster Recovery and Reconstruction of Yushu Earthquake (9 June 2010) (P.R.C. State Council 2010a), and Planning for Post-Disaster Recovery and Reconstruction of Zhouqu (4 November 2010) (P.R.C. State Council 2010b). In integrated disaster risk management, the government has taken the responsibility of planning in coordinating development and disaster reduction, enhancing resource assurance, improving disaster coping capacity through prevention and mitigation, and accelerating the development of an industry specializing in disaster reduction.

\subsection{Promoter of IDRG}

With regard to developing a safety culture, increasing societal awareness of risk governance, improving its capacity for effectively reacting to disasters, establishing post-disaster self- and mutual-assistance organizations, and allowing volunteers to play a full role are important approaches to improve the integrated governance of disaster risks. In recent years, frequent and serious disasters have drawn the attention of the whole world. International organizations, such as UNISDR (United Nations International Strategy for Disaster Reduction), have attached great importance to the establishment of a safety-minded culture. Governments of many countries have also stressed enhancing public awareness of disaster prevention and reduction as well as risk governance. In 1989, UNISDR took the lead in creating International Disaster Reduction Day (the second Wednesday in October of each year starting officially in 1991) with the aim to increase awareness of disaster prevention and reduction worldwide (Fan 2000).

After the 2008 Wenchuan Earthquake, the Chinese government marked May 12 each year as National Disaster Prevention and Reduction Day and undertook a series of informational measures promoting disaster prevention and reduction. Public awareness of disaster prevention and reduction has improved as a result. To upgrade disaster prevention and reduction education, governments at different levels in China organized diverse disaster emergency practices to increase public skills in responding to disasters. These actions promoted safety consciousness among Chinese citizens, increased the capacity for disaster prevention and reduction, promoted consciousness of risk governance, strengthened disaster reduction education, improved emergency response skills, and developed improved disaster risk governance technologies. The government demonstrably has played an active role as a promoter of integrated disaster risk management.

\subsection{Organizer of IDRG}

Integrated disaster risk management is also an important part of social management. The ability to mobilize community resources and other nongovernmental forces is critical in improving integrated disaster risk management. In an integrated disaster risk management system, the roles played by 
these forces are mainly providing assistance in a disaster area, including facilitating disaster relief donations and recovery and reconstruction assistance from institutions, organizations, and individuals, and the establishment of a risk-sharing system and partner assistance mechanism. The core positions of the government in disaster, risk, and emergency management are highlighted in the social governance system.

In strengthening integrated disaster risk management, as called for by the United Nations, the Chinese government established in April 1989 the China National Committee for IDNDR. Several existing governmental institutions and nongovernmental organizations were involved cooperatively in this organization. The committee was later transformed into the China Commission for International Disaster Reduction and the China National Committee for Disaster Reduction. These entities were fully responsible for the organization and coordination of Chinese government and nongovernmental forces in undertaking disaster prevention and reduction. To mobilize communities and other nongovernmental organizations, and to provide an operating structure within which these entities can work cooperatively, the Chinese government has put in place a comprehensive legislative structure (Table 1). The goal of this legislation is to channel government agencies and NGOs into an integrated policy structure that facilitates rapid and effective disaster coping, mitigation, and recovery activities. To strengthen the organization and management of volunteers, upon approval of the Ministry of Civil Affairs, the All-China Volunteers Association was established in 2011. For the purpose of deploying nongovernmental forces in integrated disaster risk management, governments at different levels have not only played the role of the organizer in disaster, risk, and emergency management, but also have played a prominent role in mobilizing these forces to work on disaster prevention and reduction. By leading, planning, promoting, and organizing integrated disaster risk management, in the process of strengthening political, economic, cultural, and social developments, the government enhances its functions, practices its leading role in IDRG, and actualizes its services for the public and its leadership in managing public utilities.
Compared to countries with a capitalist market economy such as the United States of America, Japan, Germany, and the United Kingdom, the role of the Chinese government, especially the central government, in IDRG is much more dominant. The government is still the single sovereign authority on decision making as well as implementation of disaster risk management actions, from legislation, to emergency response, to prevention and mitigation.

\section{The Collaborating and Integrating Role of Government in IDRG}

Driven by globalization and a networked society, in IDRG the government not only plays the role of a leader but also through system design creates an open environment for different stakeholders throughout society to realize their maximum effect in achieving disaster risk prevention and reduction. The government encourages a more transparent process by promoting innovative mechanisms and connections in the disaster risk governance system. Aware that a transparent and inclusive process enables all stakeholders to participate effectively, the government coordinates different forces to form a joint response force to disaster risks at different hazard levels so as to maximize the utilization benefits of disaster reduction resources. Additionally, legislation should be improved to integrate different resources so that all the segments of society responding to disaster risks are seamlessly linked vertically and horizontally. The development of these connections maximizes the utilization efficiency of disaster reduction resources. Facing different disaster risks, a government focusing on the interests of the people and the state should maximize the utilization efficiency and benefits of different resources for disaster risk governance. Only by taking efficiency or benefit as the first priority will the government play a better collaborating and integrating role in IDRG. In the age of inclusive development, the government must play a collaborating and integrating role in IDRG so as to carry out the guiding principle of providing all-around assistance to disaster victims, promoting what is beneficial, and avoiding what is harmful in IDRG.

Table 1. Examples of disaster prevention and reduction legislation

\begin{tabular}{|c|c|c|}
\hline Date & Name of Legislation & Responsible Agency \\
\hline 1 Jun. 1994 & Notice for Taxation on Issuing Income of Bonus Donations for Social Welfare & State Bureau of Taxation, P.R.C. (1994) \\
\hline 5 Aug. 1998 & $\begin{array}{l}\text { Notice for Distributing the "Provisional Measures for Exemption of Import Duties for } \\
\text { Goods Donated for Disaster Relief" }\end{array}$ & $\begin{array}{l}\text { General Administration Customs, P.R.C. } \\
\text { (1998) }\end{array}$ \\
\hline 22 Sept. 1998 & Circular on Deduction before Income Tax for Donations of Enterprises to Disaster Areas & State Bureau of Taxation, P.R.C. (1998a) \\
\hline 17 Dec. 1998 & Circular on Exemption of Personal Income Tax for China Welfare Disaster Relief Lottery & State Bureau of Taxation, P.R.C. (1998b) \\
\hline 1 Sept. 1999 & Welfare Donations Law of the People's Republic of China & $\begin{array}{l}\text { Standing Committee of the National } \\
\text { People's Congress, P.R.C. (1999) }\end{array}$ \\
\hline 12 May 2000 & Provisional Administrative Measures for Disaster Relief Donations & Ministry of Civil Affairs, P.R.C. (2000) \\
\hline 7 May 2005 & Circular on the Preferential Taxation Policies for Rescue and Salvage Units & $\begin{array}{l}\text { Ministry of Finance, General Administration } \\
\text { of Customs, and State Bureau of Taxation, } \\
\text { P.R.C. (2005) }\end{array}$ \\
\hline 28 Apr. 2008 & Administrative Measures for Disaster Relief Donations & Ministry of Civil Affairs, P.R.C. (2008) \\
\hline 1 Jul. 2008 & $\begin{array}{l}\text { Regulations of the People's Republic of China for Military Forces to Participate in Rescue } \\
\text { and Disaster Relief }\end{array}$ & $\begin{array}{l}\text { State Council and Central Military } \\
\text { Committee, P.R.C. (2008) }\end{array}$ \\
\hline
\end{tabular}




\subsection{Integration of Government and Nongovernmental Organizations}

Politically, relevant governmental organizations play an important role in IDRG, but many nongovernmental organizations also have an important role. In disaster prevention and reduction and risk management, NGOs have made many important contributions to the study of disaster risks and have played an important supporting role in implementing disaster prevention and reduction measures based on scientific research and development. NGOs also have played an irreplaceable role in disaster emergency relief. Many volunteer organizations carry out an extremely important complementary role to governmental organizations during and after disasters. Particularly notable is their role in distributing disaster relief goods, caring for the injured, clearing disaster sites, and participating in and assisting with the recovery and reconstruction of disaster areas. Worldwide, an increasingly large number of NGOs are involved in integrated community disaster risk management and have become vital in community disaster prevention and reduction. NGOs such as the International Red Cross and Red Crescent Societies are a major force in disaster emergency relief and community disaster prevention and reduction, with excellent reputations based on engagement in disaster areas worldwide. Many charitable organizations have been formed in China, and they play an invaluable role in disaster prevention and reduction in the country. This is especially the case in rescue and relief responses to recent serious and major disasters. Governmental and nongovernmental organizations should be integrated in order to optimize the structure of organization and improve their functions in disaster prevention and reduction to maximize their effects in IDRG.

\subsection{Consolidation of Governmental and Nongovernmental Resources}

The Chinese government has invested huge resources into strengthening safety conditions, improving disaster rescue and relief, enhancing rapid emergency response, and promoting risk transfer. As a result of these efforts, the regional capacity of IDRG has thus improved significantly. But in taking a worldwide view of the whole process of disaster preparation, emergency response, and recovery and reconstruction, it is clear that governmental resources alone can hardly meet the increasing demand for integrated disaster prevention, reduction, and risk governance. The reality is that in a majority of countries and regions, disaster protection is low, input for disaster relief is inadequate, and emergency response capacity is weak. Nongovernmental resources available for disaster prevention and reduction and disaster risk management often lack systematic management. In developed countries, where disaster insurance systems have been founded with society-wide enthusiasm, there is a massive capacity for disaster risk transfer. By issuing catastrophe bonds and running a catastrophe lottery, nongovernmental resources have been mobilized for active disaster prevention and reduction and disaster risk governance.

For disaster preparation, in addition to the reserves of emergency and disaster relief goods prepared by the government, community organizations and households can help reduce the pressure on governments at different levels by storing disaster relief goods according to the local disaster type and disaster risk level. Establishing a community reserve system in collaboration with the governmental emergency reserve system greatly increases regional emergency response capacity. Integration of governmental and nongovernmental resources improves the capacity of resource assurance for IDRG. These pooled resources also increase massively the utilization efficiency of governmental resources for disaster prevention and reduction and emergency relief. This integrated approach is critical for the Chinese government's "national response to catastrophe" principle (Shi and Liu 2009).

Learning from the experiences of different countries in undertaking catastrophe financing, with the energetic support of its national treasury, the Chinese government has strengthened disaster insurance for agriculture and buffers both farmers and businessmen from excessive disaster risk. In 2009, agricultural insurance amounted to RMB 381 billion Yuan and the premiums received amounted to RMB 13.4 billion Yuan. Through exposure to the system over the last four years, the government-supporting and market-operating agricultural disaster insurance model implemented by the Chinese government has been gradually but widely accepted by Chinese society.

\subsection{Integration of Majority and Minority Cultures}

The establishment of the safety-minded culture advocated by governments and relevant UN organizations has always been the mainstream culture of IDRG practitioners. But owing to the imbalance in social and economic development between different countries and varied disaster risk perceptions in traditional cultures even within a single country, the differences in safety culture remain prominent. It is imperative to incorporate traditional disaster prevention and reduction and risk management methods that have evolved in countries around the world when establishing a global safety culture. The ideology of "harmony of heaven, earth, and man" and "harmony of nature and man" in Chinese traditional culture plays an important guiding role for the Chinese nation as it establishes a modern culture for disaster prevention and reduction and disaster risk governance. By integrating disaster prevention and reduction into school education and by expanding public dissemination of disaster information and education, it is possible to increase dramatically the public's awareness of disaster risk governance and how to respond to a disaster. Combined efforts to emphasize culturally different and traditional ways of coping with disasters in forming national disaster risk reduction cultures and promotion of school and public education about disaster risk reduction accelerates the formation of a top-down and bottom-up IDRG and 
establishes a good cultural atmosphere for national and community level disaster risk governance.

\subsection{Integration of Advantaged and Disadvantaged Social Groups}

Socially and economically less developed regions, especially communities in poverty-stricken areas, are usually susceptible to the adverse effects of disasters. In contrast, socially and economically developed regions, especially communities with a highly developed safety level, are usually more resilient. When coping with any disaster, the government must treat equally and grant the same relief to both strong groups (of relatively high income) and weak groups (of relatively low income) at risk in the disaster. It is perhaps even more important to keep at the forefront of concern the needs of the less advantaged social elements because these communities would be the groups more often in the most desperate need. It is important to create a good environment and establish a mechanism for relief and reconstruction assistance partnership between non-disaster regions and disaster areas.

After the Wenchuan Earthquake, the partner reconstruction assistance mechanism played an important role in the quick recovery and reconstruction that followed. In any disaster, the mode of social management employed to integrate weak groups (low-income groups and communities in disaster areas) and strong groups (high-income groups and communities in non-disaster regions) is important. This integrated approach is vital not only in emergency rescue and recovery and reconstruction of the disaster area, but also in stabilizing society and securing sustainable economic development in the region.

By integrating organizations, resources, cultural heritage, and social management, the government collaborates with and integrates resources from different sectors for disaster risk management. This comprehensive structure involves all stakeholders in the process of political, economic, cultural, and social development in order to achieve the common goal of increasing the utilization efficiency and benefit of available resources.

\section{International Humanitarian Role of the Government in IDRG}

In an age of increasingly accelerating globalization and regional and global-wide disasters, there has been a sharp increase in the number and magnitude of catastrophes. How can the global impact of disaster risks be governed? What strategy should the international community formulate for disaster prevention and reduction? What measures need to be taken for disaster prevention and reduction? All the major issues relating to integrated disaster risk management urge the governments of different countries to place more importance on their role as an international humanitarian entity. This transnational humanitarian perspective strengthens the global governance of disaster risks and especially catastrophe risks, increases the input of relief and assistance to disasteraffected areas, and makes possible greater contributions to sustainable development worldwide.

\subsection{Disaster Reduction Diplomacy}

Politically, the diplomacy of disaster reduction is an important task. As the internet has developed and its use has expanded, economic globalization has taken place, and transnational production has grown continually, dependence among countries has greatly increased. For many political, economic, cultural, and social reasons, there has been a growth in terrorist organizations, pirate communities, and cult groups. These social responses have been accompanied by the emergence of global climate change as represented by global warming, and the outbreak of regional conflicts or wars. All of these developments worsen the impacts of natural disasters. Once a region or country suffers a serious disaster, it will soon affect the surrounding region and the effects will spread promptly all over the world, making the disaster more extensive and difficult to govern.

As part of world diplomacy, there is now a gradually growing appreciation for the diplomacy of disaster reduction, which includes a response to climate change and a crackdown on terrorist organizations, as well as an understanding that such diplomacy is urgently required. While placing full importance in disaster reduction on the coordinating role of different bilateral exchange mechanisms, regional and international organizations, and the United Nations, it is necessary to strengthen the political construction of disaster reduction diplomacy in different countries by establishing bilateral and multilateral trust mechanisms. These multifaceted efforts are in line with the strategic target of benefiting all of mankind and are based on humanist principles. Such principles advocate the United Nations as the central institution to promote the establishment of a global IDRG system. These efforts combine to reduce or eliminate political barriers to increasing worldwide integrated disaster prevention and reduction policies. The effort to build an international disaster prevention and response system places great emphasis on carrying out a subtle and sophisticated disaster reduction diplomacy.

\subsection{Improving the Catastrophe Financial Guarantee System}

The construction of a catastrophe financial guarantee system is an important task. Catastrophe financing in many countries has adequately proven that implementation of catastrophe insurance, catastrophe bonds, and a catastrophe lottery under governmental support are effective financial measures for disaster risk governance. There is an urgent need to strengthen governmental support through fiscal measures, taxation, credit, and guarantees in order to establish a catastrophe financial guarantee system so that companies managing disaster reduction products can make ends meet, make a 
reasonable profit, and prepare for future catastrophes. The connection of the domestic guarantee system to international financial services such as international insurer, cat-bond issuer, as well as the capital market, would also significantly increase the resilience against catastrophic impacts of the system. Should a catastrophe occur, these supports will enable governments and businesses to beat the odds together internationally.

\subsection{Strengthening Education and Research of IDRG}

Establishing a culture of disaster prevention and reduction and disaster risk governance is also an important task. Based on the international humanitarian spirit, the government needs to strengthen information provision and development of disaster relief donations, sponsor growth of a volunteer culture, and establish a disaster risk governance culture of all-around assistance to disaster victims. To create consciousness of the necessity to achieve concurrent economic and human development and disaster reduction goals, the government must promote and increase education level in disaster risk governance. To strengthen integrated studies of disaster risk, the international community has established two global scientific programs for integrated disaster risk research: the IHDP-IRGP (International Human Dimensions Programme for Global Environmental Change-Integrated Risk Governance Project), which is implemented by the IHDP; and the ICSU-IRDR (International Council for Science-Integrated Research on Disaster Risk) program, which is implemented by ICSU and other organizations. Strengthening studies of IDRG and energetically pushing forward the sharing of IDRG knowledge are equally important goals. A series of relevant gateway websites have been built, such as www.irisknet.cn built with the support from the Ministry of Science and Technology of China, and www.PreventionWeb.net and www.relief.int built by the UNISDR. Under the guidance of international humanitarianism, the governments of different countries have strengthened the popularization, education, and scientific research of IDRG.

\subsection{Increasing the Capacity for International Disaster Assistance}

Increasing the capacity of international disaster relief and assistance is also an important task. International rescue is one reflection of international humanitarianism and an important task for different countries, and increasing the capacity of IDRG is reflective of an attitude of all-around assistance to disaster victims. Owing to different levels of social and economic development in countries around the world as well as large differences in per capita income, the capacity of international rescue has been restricted to some extent. There are different views on whether economically developed countries should be granted assistance in the event of a disaster. But once a catastrophe occurs, even economically developed countries, such as Japan after the 11 March 2011 earthquake and tsunami, need assistance from other countries. In the aftermath of a disaster, socially and economically less developed countries need other countries and regions to provide humanitarian assistance. Increasing the service capacity of volunteers has become a social project that has recently developed rapidly in different countries. The need to provide volunteer assistance is an important challenge to various governments around the world who must strengthen their social management in order to meet expectations. By extensively learning from the worldwide experiences of volunteer organizations, China has placed importance not only on the role of volunteer services during major public events such as the 2008 Beijing Olympic Games and the 2010 Shanghai World Expo, but also on the functions of volunteer services in responding to recent serious and major disasters. Great numbers of volunteers in China have made outstanding contributions to emergency rescue in and relief of disaster areas domestically. It is foreseeable that volunteer services eventually will also play a role in China's international disaster assistance.

Government can play an international humanitarian role in IDRG and achieve peace with other countries while providing these countries with assistance for their inclusive development. It can do this through disaster reduction diplomacy, consolidating a catastrophe financial guarantee system, strengthening the education and research of IDRG, and improving the capacity of international disaster relief. Of equal importance is the need to direct attention onto different parties and perfect the functions of relevant actions in the process of political, economic, cultural, and social development.

\section{Conclusion}

This article has outlined the role of the government in IDRG based on the practices in China. In political, economic, cultural, and social development, by leading, planning, promoting, and organizing IDRG, the government enhances its own functions in disaster risk governance and promotes the general welfare of society. The government accomplishes this goal through the integration of organizations, resources, culture, and social management. It also increases the efficiency and benefits of resource use for IDRG and plays a collaborating and integrating role in IDRG. The government engages in disaster reduction diplomacy, establishes a catastrophe financial guarantee system, and strengthens the education and research of IDRG. By increasing the capacity of international disaster relief, the government plays an international humanitarian role in disaster situations. The government remains the predominant actor shaping the Chinese mode of disaster risk governance, which employs largely state-centric approaches to cope with disaster risks.

The role of the government in IDRG is not exclusive. Only by actualizing its leading, collaborating, integrating, and international humanitarian roles in the system of IDRG, while 
appreciating the importance of business, communities, and the public in disaster risk management, will it be possible for the government to improve the structure and functions of the IDRG system, and maximize the efficiency and benefits of the use of available disaster reduction resources.

\section{Acknowledgment}

This work is funded by the National Scientific Plan for Global Change Research-Relations between Global Change and Environmental Risk and Its Adaptive Paradigm (2012CB955404).

\section{References}

Beck, U. 1992. The Risk Society: Toward a New Modernity. London: Sage.

2006. Reflexive Governance: Politics in the Global Risk Society. In Reflexive Governance for Sustainable Development, edited by J. VoB, D. Bauknecht, and R. Kemp, 31-56. Cheltenham: Edward Elgar Publishing.

Biermann, F., K. Abbott, S. Andresen, K. Bäckstrand, S. Bernstein, M. M. Betsill, H. Bulkeley, B. Cashore, et al. 2012. Navigating the Anthropocene: Improving Earth System Governance. Science 335 (6074): 1306-07.

Biermann, F., B. Siebenhüner, and A. Schreyögg. 2009. International Organizations in Global Environmental Governance. Abingdon, United Kingdom: Routledge.

Fan, B. J., ed. 2000. Memoir of IDNDR in China. Beijing: Contemporary China Publishing House (in Chinese).

IRGC (International Risk Governance Council). 2005. Risk Governance: Towards an Integrative Approach. White Paper No. 1. Geneva: IRGC.

- 2008. An Introduction to the Risk Governance Framework. Geneva: IRGC.

2009. Risk Governance Deficits: An Analysis and Illustration of the Most Common Deficits in Risk Governance. Geneva: IRGC.

$\mathrm{Li}, \mathrm{F}$., ed. 2007. Interpretation and Practical Guidance of the Emergency Response Law of the People's Republic of China. Beijing: China Democracy and Legal Affairs Publishing House (in Chinese).

People's Republic of China (P.R.C.). General Administration of Customs. 1998. Notice for Distributing the "Provisional Measures for Exemption of Import Duties for Goods Donated for Disaster Relief". http://www.chinatax.gov.cn/n480462/n480513/n480979/ n554124/996071.html (in Chinese).

- IDNDR (China National Committee for the International Decade for Natural Disaster Reduction). 1998. Disaster Reduction Planning of the People's Republic of China (1998-2010). http://www. law-lib.com/law/law_view.asp?id=66902 (in Chinese).

- Ministry of Civil Affairs. 2000. Provisional Administrative Measures for Disaster Relief Donations. http://www.gov.cn/ztzl/200512/31/content_143932.htm (in Chinese).

- Ministry of Civil Affairs. 2008. Administrative Measures for Disaster Relief Donations. http://www.mca.gov.cn/article/zwgk/fvfg/ jzjj/200805/20080500014136.shtml (in Chinese).

. Ministry of Finance, General Administration of Customs, and State Bureau of Taxation. 2005. Circular on the Preferential Taxation Policies for Rescue and Salvage Units. http://www.mof.gov.cn/ mofhome/mof/zhengwuxinxi/caizhengwengao/caizhengbuwengao 2005/caizhengbuwengao20055/200805/t20080525_42754.html (in Chinese).

- National Development and Reform Commission and National Disaster Reduction Committee. 2011. National 12th Five-Year Integrated Disaster Reduction Plan (2011-2015). http://www.gov.cn/ zwgk/2011-12/08/content_2015178.htm (in Chinese).

_. Standing Committee of the National People's Congress. 1999. Welfare Donations Law of the People's Republic of China. http:// www.gov.cn/ziliao/flfg/2005-10/01/content_74087.htm (in Chinese). - Standing Committee of the National People's Congress. 2007. Emergency Response Law of the People's Republic of China. http:// www.gov.cn/ziliao/flfg/2007-08/30/content_732593.htm (in Chinese). - State Bureau of Taxation. 1994. Notice for Taxation on Issuing Income of Bonus Donations for Social Welfare. http://www.chinatax. gov.cn/n480462/n480513/n480979/n554109/999313.html (in Chinese). . State Bureau of Taxation. 1998a. Circular on Deduction before Income Tax for Donations of Enterprises to Disaster Areas. http:// www.chinatax.gov.cn/n480462/n480483/n480675/n592890/n593099/ 1020478.html (in Chinese).

- State Bureau of Taxation. 1998b. Circular on Exemption of Personal Income Tax for China Welfare Disaster Relief Lottery. http://www.people.com.cn/item/flfgk/gwyfg/1998/215412199817. html (in Chinese).

State Council. 2006. General Emergency Response Program for State Accidental Public Events. http://www.china.com.cn/chinese/ law/1086058.htm (in Chinese).

- State Council. 2008. Guidelines for Planning of Recovery and Reconstruction after Freezing Rain Disaster. http://www.sdpc.gov. $\mathrm{cn} / \mathrm{xwfb} / \mathrm{t} 20080228$ 194548.htm (in Chinese).

- State Council. 2010a. Planning for Post-Disaster Recovery and Reconstruction of Yushu Earthquake. http://www.gov.cn/zwgk/201006/13/content 1626853.htm (in Chinese).

- State Council. 2010b. Planning for Post-Disaster Recovery and Reconstruction of Zhouqu. http://www.gov.cn/zwgk/2010-11/10/ content 1742124.htm (in Chinese).

- State Council and Central Military Committee. 2008. Regulations of the People's Republic of China for Military Forces to Participate in Rescue and Disaster Relief. http://www.gov.cn/ zwgk/2005-06/24/content 9347.htm (in Chinese).

Renn, O. 2008. Risk Governance: Coping with Uncertainty in a Complex World. London: Earthscan.

Renn, O., A. Klinke, and M. van Asselt. 2011. Coping with Complexity, Uncertainty and Ambiguity in Risk Governance: A Synthesis. AMBIO 40 (2): 231-46.

Shi, P. J. 2009. Fifth Discussion on Theory and Practice for Systematic Studies on Disasters. Journal of Natural Disasters: 18 (5): 1-9 (in Chinese, with English summary).

Shi, P. J., N. Li, Q. Ye, W. J. Dong, G. Y. Han, and W. H. Fang. 2010. Research on Integrated Disaster Risk Governance in the Context of Global Environmental Change. International Journal of Disaster Risk Science 1 (1): 17-23.

Shi, P. J., and Y. H. Liu. 2009. Chinese Paradigm for Catastrophe Risk Governance. Journal of US-China Public Administration 6 (6): $18-28$.

Shi, P. J., L. D. Shao, Z. G. Zhao, and Q. X. Huang. 2007. On Integrated Disaster Risk Governance: Seeking for Adaptive Strategies for Global Change. Earth Science Frontiers 14 (6): 43-53 (in Chinese, with English summary).

Walker, G., R. Whittle, W. Medd, and N. Watson. 2010. Risk Governance and Natural Hazards. CapHaz-Net WP2 report. http://caphaznet.org/outcomes-results/CapHaz-Net WP2 Risk-Governance2.pdf.

Zheng, G. C. 2009. State Development with Various Disasters: Epic of Disaster Resistance in the Six Decades of New China. Changsha: Hunan People's Publishing House (in Chinese).

Open Access This article is distributed under the terms of the Creative Commons Attribution License which permits any use, distribution, and reproduction in any medium, provided the original author(s) and source are credited. 